\title{
Indacaterol, A Novel Once Daily Inhaled 乃2-Adrenoreceptor Agonist
}

\author{
Jorge Roig ${ }^{*}, 1$, Rosana Hernando ${ }^{2}$ and Ramon Mora \\ ${ }^{1}$ Servei de Pneumologia, Hospital Nostra Senyora de Meritxell, Escaldes, Andorra, Spain \\ ${ }^{2}$ Servei de Pneumologia, Hospital Comarcal Sant Joan de Deu, Sant Boi de Llobregat, Barcelona, Spain
}

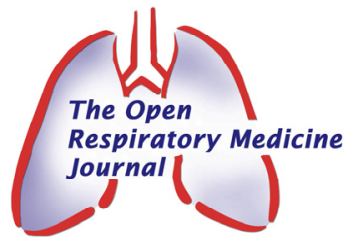

\begin{abstract}
In this article we will review the role of long acting $\beta 2$-adrenoreceptor agonists and long-acting muscarinic agents in the management of airflow obstruction. We will then focus our attention on indacaterol, one of the new once daily inhaled $\beta 2$-adrenoreceptor agonists. Pharmacologically this drug is a nearly full $\beta 2$-agonist without loss of efficacy after prolonged administration. We will also discuss its dosing, safety and tolerability.
\end{abstract}

Keywords: Indacaterol, tachyphylaxis, activity profile, safety.

\section{ROLE OF LONG ACTING B2-ADRENORECEPTOR AGONISTS AND LONG-ACTING MUSCARINIC AGENTS IN THE MANAGEMENT OF AIRFLOW OBSTRUCTION}

International guidelines on chronic obstructive pulmonary disease (COPD) and bronchial asthma $[1,2]$ underline the clinical benefit derived from including long acting bronchodilators in their therapeutic approach. The current gold standard therapy for treating patients with moderate-tosevere persistent asthma is the combination of a long acting $\beta 2$-adrenoreceptor agonist (LABA) with an inhaled corticosteroid. Long acting $\beta 2$-adrenoreceptor agonists (LABAs) have also a well established role in the treatment of stable COPD. It is well known that a simplified dosing regimen will improve patients' compliance [3], a key point in multistep therapeutic regimens such as those that are often prescribed to individuals with COPD or asthma. That is why long acting agents, particularly once-daily inhalers, will offer a better adherence than other drugs that require a more complicated dosing schedule.

LABAs are highly lipophilic compounds. This characteristic helps to prolong their duration of action since they dissociate more slowly than short-acting $\beta 2$-agonists from lung fat-soluble tissues. Formoterol and salmeterol have been the LABAs usually prescribed by most clinicians during the last decades [4]. However, a few drugs have been developed for the last years to attempt to improve the therapeutic profile of these classical LABA. Ultra-LABA is the term used to describe a variety of new $\beta 2$-adrenoreceptor agonists that have focused their action in a more prolonged half life with the aim of making feasible a one-day dose administration. Indacaterol (QAB-149), carmoterol (CHF-4226, TA-2005), GSK-159797, and GSK-642444 are some of these new ultra-LABAs that are still in different phases of clinical development $[5,6]$.

*Address correspondence to this author at the Servei de Pneumologia, Hospital Nostra Senyora de Meritxell, AD700 - Escaldes, Andorra, Spain; Fax:+376829627; E-mail: jroig@separ.es
Parallel to what happens with $\beta 2$-adrenoreceptor agonists new long acting antimuscarinic agents (LAMAs) are also under preclinical development in an attempt to improve some aspects of the excellent therapeutic profile that tiotropium has shown since this drug has become commercially available [7]. Aclidinium, NVA237, OrM3, and CHF 5407 are some of these new LAMAs which are also in different phases of preclinical development. The combination of a long acting $\beta 2$-adrenoreceptor agonist (LABA) and a longacting muscarinic agent (LAMA) is an innovative approach that will most likely be a significant therapeutic progress in a selected population of patients with airflow obstruction. However, further studies are clearly warranted before we can define which population of patients will really benefit from these future therapeutic combined agents.

This review focuses on indacaterol (QAB 149; Novartis, Basel, Switzerland) [8, 9], one of the new once daily inhaled $\beta 2$-adrenoreceptor agonists that has completed phase II and phase III clinical trials for the treatment of asthma and COPD.

\section{INDACATEROL: ACTIVITY PROFILE}

Pharmacologically, indacaterol is a nearly full $\beta 2$-agonist [10]. Tissue and experimental studies show longer durations of action for indacaterol when compared to salmeterol or formoterol, demonstrating sustained bronchodilator efficacy throughout the full 24-hour period [11, 12]. In a human lung slice model Sturton et al. [13] have demonstrated that indacaterol has a superior activity than salmeterol and a similar intrinsic efficacy to formoterol. Onset of action, with a fast acting action, is very similar for indacaterol and formoterol and slower for salmeterol. This experimental finding correlates well with what has been observed in initial clinical studies, since a statistically significant beneficial effect is demonstrated in those patients receiving indacaterol within the first 5 minutes after inhalation. A rapid onset of effect may increase patients' confidence in treatment and subsequently improve therapy compliance. Opposite to this rapid absorption and onset of action for indacaterol, salmeterol 
improvement in $\mathrm{FEV}_{1}$ occurs within 15 minutes after inhalation. Functional data show highest, about twofold, intrinsic activity for formoterol and indacaterol than for salbutamol or salmeterol [8].

\section{INDACATEROL: DOSING}

Rennard et al. [14] conducted a dose-ranging study, with a tiotropium comparison, to elucidate which dose of indacaterol shows 24-hour effectiveness in patients with moderate-to-severe COPD. Functional inclusion criteria were prebronchodilator $\mathrm{FEV}_{1} \geq 40 \%$ of predicted, $\mathrm{FEV}_{1} \geq 1.0 \mathrm{~L}$, and $\mathrm{FEV}_{1} / \mathrm{FVC}<70 \%$. Six hundred thirty five patients were eventually randomized to receive $50,100,200$ or $400 \mu \mathrm{g}$ or placebo once daily for 7 days. All indacaterol doses significantly increased $\mathrm{FEV}_{1}$ from 5 minutes to 24 hours post-dose but 400 and $200 \mu \mathrm{g}$ were the dose most effective. A subset of subjects from each treatment group entered an open label extension and received tiotropium $18 \mu \mathrm{g}$ once daily for 8 days. Indacaterol through FEV1 levels compared favorably with the improvement observed by day 8 in patients that received tiotropium in this subgroup of patients taking part in the open-label extension. Overall, a $400 \mu \mathrm{g}$ dose was the most effective in this study.

Single $200 \mu \mathrm{g}$ and $400 \mu \mathrm{g}$ doses provide effective and sustained 24-hour bronchodilator control and a rapid onset of action ( $<5$ minutes) in asthmatic patients. A $200 \mu \mathrm{g}$ dose seems to be the optimum dose regarding efficacy and safety balance. On another dose-ranging study designed to establish the optimal dose for indacaterol inhaled treatment in patients with persistent asthma, LaForce et al. [15] also reported that a $200 \mu \mathrm{g}$ dose seems to offer the best efficacy/safety balance in most subjects.

\section{INDACATEROL: TACHYPHYLAXIS}

It has been stated that $\beta_{2}$ adrenoreceptor downregulation may follow chronic administration of LABAs in asthma. The consequence would be a subsequent reduced sensitivity, known as tachyphylaxis, of airway smooth muscle and inflammatory cells response. It must be emphasized that tachyphylaxis has not been observed with long-term indacaterol administration. Many studies have shown that there is no loss of efficacy with prolonged administration of indacaterol since sustained improvements on $\mathrm{FEV}_{1}$ are consistently observed in those clinical trials that have addressed this issue. A low need of rescue medication in the indacaterol arm has also been occasionally highlighted in some comparative clinical trials of indacaterol and other LABAs.

\section{INDACATEROL: INTERACTION WITH SHORT ACTING BETA $A_{2}$-ADRENERGIC AGENTS (SABAs)}

The interaction of indacaterol, formoterol and salmeterol with the short acting adrenergic agent isoprenaline was evaluated by Naline et al. [16] on a nice study with isolated human bronchi. These authors show that indacaterol and formoterol behave as full agonists and do not antagonize the isoprenaline-induced bronchi relaxation response in an isolated human bronchi model using preparations precontracted with carbachol. The lack of antagonism with short-acting agonists may have potential clinical connotations regarding the use of SABA as rescue therapy in com- mon clinical practice. Other findings from the study reported by Naline et al. [17] were that indacaterol showed an onset of action similar to that of salbutamol and duration of action $>12$ hours.

\section{INDACATEROL}

Previous studies in patients and healthy volunteers have shown that LABAs may be associated with $\beta_{2}$ mediated systemic adverse effects such as skeletal muscle tremor, headache, nervousness, palpitations with changes in heart rate, prolongation of the QTc interval, and increased glucose and potassium blood levels [18-25]. On the basis of these data, safety and tolerability studies have been conducted to evaluate indacaterol effect on these parameters. An optimal safety profile is mandatory for a drug, such as indacaterol, characterized by a 24-hour bronchodilator efficacy at oncedaily dosing.

In asthma patients' indacaterol offers an excellent overall safety profile since even a high dose of $1000 \mu \mathrm{g}$ has not been found to be associated with any sustained systemic adverse effect [26-28]. It is worthwhile pointing out that a dose of $1000 \mu \mathrm{g}$ is obviously a clearly supratherapeutic dosing, which is five-fold the standard dose in asthma; this feature deserves to be emphasized since in clinical practice some patients may self-administer additional doses of the drug as rescue medication or accidentally.

In the COPD setting, once-daily indacaterol at doses up to $800 \mu \mathrm{g}$ has been well tolerated. A prospective randomized comparative study on 163 patients with COPD receiving placebo or $400 \mu \mathrm{g}$ or $800 \mu \mathrm{g}$ of indacaterol did not show any statistically significant difference at any dose on mean pulse rate and QTc interval [29]. As it has been observed in safety studies in asthma population [30], small differences, considered to be without any clinical relevance, were found on serum potassium levels, mean blood glucose levels and mean blood pressure.

Although no serious adverse effects are found in safety studies on indacaterol, mild cough is a relatively common adverse effect [31]. A short duration, less than 2 minutes post-dose, and the lack of bronchospasm of any degree are distinctive features of this indacaterol-induced cough. It has been reported in up to $14.7 \%$ of patients receiving this inhaled drug at a dose of $400 \mu \mathrm{g}$ daily and in up to $28.4 \%$ in those receiving an $800 \mu \mathrm{g}$ daily dose. It is worthwhile remembering that an $800 \mu \mathrm{g}$ dose represents at least 2 times the usual therapeutic dose suggested by initial studies. In a different series of COPD patients treated with more standard doses of indacaterol mild and short-lived cough occurred in a dose-related form, with an incidence that ranged from $2.9 \%$ with a $50 \mu \mathrm{g}$ dose to $12.4 \%$ with a $400 \mu \mathrm{g}$ dose. This cough is almost always of mild intensity; it usually appears with initial administration of the drug and declines progressively after a few days of treatment. In the study published by Rennard et al. [14] the incidence of cough by day 7 was similar to that observed with placebo. More interestingly, by the first month of treatment no patients receiving indacaterol complain about cough.

Researchers have realized that a very low drop-out rate has been consistently observed in the indacaterol arm of most comparative clinical trials, a data that suggests itself the 
good safety and tolerability profile of this inhaled ultraLABA. However, a word of caution is still warranted since a common pitfall of most new LABAs trials, including those that focus on indacaterol, is that the duration of the studies is in general relatively short. Consequently, more long-term studies are warranted to definitely confirm its impressive bronchodilator efficacy and continued safety over time.

\section{PRESSURIZED METERED-DOSE INHALER (MDI) VERSUS SINGLE-DOSE DRY POWER INHALER (SDDPI)}

Indacaterol has proven to be equally effective given either by hydrofluoroalkane (HFA) pressurized metered-dose inhaler or single-dose dry power inhaler. A recent study on patients with COPD has established the SDDPI as the preferred system to inhale the drug and this device will be the usual way of administering indacaterol when the drug becomes commercially available [32]. Moreover, dosages used in this last study $(150 \mu \mathrm{g}, 300 \mu \mathrm{g}$ and $600 \mu \mathrm{g})$ will also most likely be the recommended doses when the drug eventually comes out.

\section{COMBINATION THERAPY WITH INDACATEROL AND NVA237 (GLYCOPYRROLATE)}

As stated before, preliminary reports suggest that the combination of a LABA and a LAMA may provide a therapeutic benefit in some patients with chronic airflow obstructions although this potential benefit has not been consistently identified in all published studies that have addressed this issue. It well could be that the choice of both a determined long acting $\beta 2$-adrenoreceptor agonist and a long-acting muscarinic agent is one of the potentially crucial variables to explain some of the discrepancies found among different studies. A fixed dose combination of indacaterol and NVA237 for once-daily treatment of COPD is also under development. Ongoing clinical trials using this combination will certainly help to clarify this subject in the future.

There is some evidence suggesting an optimal safety profile for NVA237: a low systemic absorption is one of the pharmacokinetic characteristics of inhaled NVA237 and it is associated with a low effect of this drug on cardiovascular parameters when compared to tiotropium [33]. Although this finding supports a more favorable safety profile for NVA237 it still remains unclear if this difference really may imply any clinically significant impact on common clinical practice. Improvements in lung function with NVA237 seem to be comparable to those observed with tiotropium [34] but inhaled NVA237 does not produce the dry mouth side effect that is often reported with other antimuscarinic drugs. Phase III studies have shown a rapid onset, about 5 minutes postdose, of bronchodilator effect. A sustained improvement if FEV1 has been observed when a dose $\geq 120 \mu \mathrm{g}$ of NVA237 has been administered in these studies.

\section{REFERENCES}

[1] Rabe KF, Hurd S, Anzueto A, et al. Global strategy for the diagnosis, management, and prevention of chronic obstructive pulmonary disease: GOLD executive summary. Am J Respir Crit Care Med 2007; 176: 532-55.

[2] Bateman ED, Hurd SS, Barnes PJ, et al. Global strategy for asthma management and prevention: GINA executive summary. Eur Respir J 2008; 31: 143-78.
[3] Claxton AJ, Cramer J, Pierce CA. A systematic review of the associations between dose regimens and medication compliance. Clin Ther 2001; 23: 1296-310.

[4] Sears MR, Lötvall J. Past, present and future - $\beta 2$-adrenoceptor agonists in asthma management. Respir Med 2005; 99: 152-70.

[5] Cazzola M, Matera MG. Novel long-acting bronchodilators for COPD and asthma. Br J Pharmacol 2008; 155: 291-9.

[6] Matera MG, Cazzola M. Ultra-long-acting $\beta_{2-}$ adrenoceptor Agonists an emerging therapeutic option for asthma and COPD?. Drugs 2007; 67: 503-15.

[7] Aaron SD, Vandemheen KL, Fergusson D, et al. Tiotropium in combination with placebo, salmeterol, or fluticasone-salmeterol for treatment of chronic obstructive pulmonary disease: a randomized trial. Ann Intern Med 2007; 146: 545-55.

[8] Battram C, Charlton SJ, Cuenoud $\mathrm{B}$, et al. In vitro and in vivo pharmacological characterization of 5-[(R)-2-(5,6-Diethyl-indan-2ylamino)-1-hydroxy-ethyl]-8-hydroxy-1H-quinolin-2-one (Indacaterol), a novel inhaled $\beta_{2}$ adrenoceptor agonist with a 24-h duration of action. J Pharmacol Exp Ther 2006; 317: 762-70.

[9] Currie GP. Indacaterol Novartis/SkyePharma. Cur Opin Invest 2006; 7: 457-63.

[10] Naline E, Molimard M, Fairhurst R, Trifilieff A, Advenier C. Pharmacological characterization of indacaterol, a novel 24-hour b2-agonist, on the isolated human bronchus. Eur Respir J 2005; 26 (Suppl 49): 216S.

[11] Beeh KM, Derom E, Kanniess F, Cameron R, Higgins M, van As. Indacaterol, a novel inhaled $\beta_{2}$-agonist, provides sustained 24-h bronchodilation in asthma. Eur Respir J 2007; 29: 871-8.

[12] Pearlman DS, Greos L, La Force C, Orevillo CJ, Owen R, Higgins M. Bronchodilator efficacy of indacaterol, a novel once-daily $\beta_{2-}$ agonist, in patients with persistent asthma. Ann Allergy Asthma Immunol 2008; 101: 90-5.

[13] Sturton RG, Trifilieff A, Nicholson AG, Barnes PJ. Pharmacological characterization of indacaterol, a novel once daily inhaled $\beta_{2}$ adrenoceptor agonist, on small airways in human and rat precisioncut lung slices. J Pharmacol Exp Ther 2008; 324: 270-5.

[14] Rennard S, Bantje T, Centanni S, et al. A dose-ranging study of indacaterol in obstructive airways disease, with a tiotropium comparison. Respir Med 2008; 102: 1033-44.

[15] LaForce C, Alexander M, Deckelman R, et al. Indacaterol provides sustained $24 \mathrm{~h}$ bronchodilation on once-daily doping in asthma: a 7day dose-ranging study. Allergy 2008: 63: 103-11.

[16] Naline E, Trifilieff A, Fairhurst RA, Advenier C, Molimard M. Effect of indacaterol, a novel long-acting $\beta_{2}$-agonist, on isolated human bronchi. Eur Respir J 2007; 29: 575-81.

[17] Naline E, Zhang Y, Qian Y, et al. Relaxant effects and durations of action of formoterol and salmeterol on the isolated human bronchus. Eur Respir J 1994; 7: 914-20.

[18] Bennet JA, Tattersfield AE. Time course and relative dose potency of systemic effects from salmeterol and salbutamol in healthy subjects. Thorax 1997; 52: 458-64.

[19] Bennet JA, Smyth ET, Pavord ID, Wilding PJ, Tattersfield AE. Systemic effects of salbutamol and salmeterol in patients asthma. Thorax 1994; 49: 771-4.

[20] Maconochie JG, Forster JK. Dose-response study with high-dose inhaled salmeterol in healthy subjects. Br J Clin Pharmacol 1992; 33: 342-5.

[21] Bremmer P. Woodmarn K, Burgess C, et al. A comparison of the cardiovascular and metabolic effects of formoterol, salbutamol and fenoterol. Eur Respir J 1993; 6: 204-10.

[22] Burgess C, Ayson M, Rajasingham S, Crane J, Della CG, Till MD. The extrapulmonary effects of increasing doses of formoterol in patients with asthma. Eur J Clin Pharmacol 1998; 54: 141-7.

[23] Totterman KJ, Huhti L, Sutinen E, et al. Tolerability to high doses of formoterol and terbutaline via Turbuhaler for 3 days in stable asthmatic patients. Eur Respir J 1998; 12: 573-9.

[24] Sears MR. Adverse effects of $\beta$-agonists. J Allergy Clin Immunol 2002; 110: S322-28.

[25] Salpeter SR, Omiston TM, Salpeter EE. Cardiovascular effects of $\beta 2$-agonists in patients with asthma and COPD: a meta-analysis. Chest 2004; 125: 2309-21.

[26] Kanniess F, Cameron R, Owen R, Higgins M. Indacaterol, a novel 24-hour ßagonist, demonstrates 24-hour efficacy and is well tolerated in patients with asthma: a multiple-dose, dose-ranging study. Eur Respir J 2005; 26(Suppl 49), 253s. 
[27] Chuchalin AG, Tsoi AN, Richter K, et al. Safety and tolerability of indacaterol in asthma: a randomized, placebo-controlled 28-day study. Respir Med 2007; 101: 2065-75.

[28] Yang WH, Martinot JB, Pohunek P, et al. Indacaterol, a novel once-daily $\beta_{2}$-agonist, is well tolerated in patients with asthma: a randomized, placebo-controlled 28-day safety study. Ann Allergy Asthma Immunol 2007; 99: 555-61.

[29] Beier J, Chanez P, Martinot JB, et al. Safety, tolerability and efficacy of indacaterol, a novel once-daily $\beta_{2}$-agonist, in patients with COPD: A 28- day randomised, placebo controlled clinical trial. Pulm Pharmacol Ther 2007; 20: 740-9.

[30] Maesen FP, Costongs R, Smeets JJ, Brombacher PJ, Zweers PG. The effect of maximal doses of formoterol and salbutamol from a metered dose inhaler on pulse rates, ECG, and serum potassium concentrations. Chest 1991; 99: 1367-73.
[31] Brookman LJ, Knowles LJ, Barbier M, Elharrar B, Fuhr R, Pascoe S. Efficacy and safety of single therapeutic and supratherapeutic doses of indacaterol versus salmeterol and salbutamol in patients with asthma. Curr Med Res Opin 2007; 23: 3113-22.

[32] Bauwens O, Ninane V, Van de Maele B, et al. 24-hour bronchodilator efficacy of single doses of indacaterol in subjects with comparison with placebo and formoterol. Curr Med Res Opin 2009; 25: 463-70.

[33] Cooper N, Walker I, Knowles I. NVA237 and tiotropium bromide demonstrate similar efficacy in $\mathrm{n}$ anesthetized rabbit model of methacholine-induced bronchoconstriction. NVA237 demonstrates a a reduced systemic pharmacological effect on cardiovascular parameters. Proc Am Thorac Soc 2006; 3: A117.

[34] Kun P, Vinkler I, Overend T, Snape S, Tansley R. Efficacy and tolerability of NVA237, a once daily long-acting muscarinic antagonist, in COPD patients. Eur Respir J 2007; 30: 354s.

Received: January 29, 2009

Revised: February 3, 2009

Accepted: February 13, 2009

(C) Roig et al.; Licensee Bentham Open.

This is an open access article licensed under the terms of the Creative Commons Attribution Non-Commercial License (http://creativecommons.org/licenses/by$\mathrm{nc} / 3.0 /$ ) which permits unrestricted, non-commercial use, distribution and reproduction in any medium, provided the work is properly cited. 